\title{
PENINGKATAN AKTIVITAS DAN HASIL BELAJAR QUR'AN HADITS MELALUI BELAJAR KELOMPOK
}

\author{
Adhar Al Mursyid \\ UIN Raden Intan Lampung \\ Email :ahdharalmursyid@gmail.com
}

\begin{abstract}
Factor motivate in studying believed very have influencing acquirement of achievement learn student. Ironically more than $60 \%$ student do not have activity for studying of Quran Hadits, so that require to be research of class action with aim to.; (1) Depicting the make-up of student activity in studying team-work.(2) Depicting the make-up of result learn student in studying teamwork. Research of this Class Action is in 3 ( three ) Rotation, in each its cycle consist of phases: planning, action, perception/ data collecting and of refleksi. To obtain get student activity data of user observer team kolabolator, and data result of learning to be obtained to tes written. Result of action indicate that team-work can improve result and activity learn student in studying of MA Darul Ulum Result of action at student activity equal to to 92.50 (Cycle one), 92.92 ( Cycle two), and 93.55 (Cycle three), and result learn student 66,77 (Cycle one), 68,40 (Cycle two), and 70,70 ( Cycle three).
\end{abstract}

Faktor motivasi dalam pembelajaran diyakini sangat mempengaruhi perolehan prestasi belajar siswa. Ironisnya lebih dari $60 \%$ siswa tidak memiliki aktivitas pembelajaran Qur'an Hadits, sehingga perlu dilakukan penelitian tindakan kelas yang bertujuan;(1) Mendiskripsikan peningkatan aktivitas siswa dalam pembelajaran melalui kerja kelompok. (2) Mendiskripsikan peningkatan hasil belajar siswa melalui kerja kelompok. Penelitian Tindakan Kelas ini dilakukan dalam 3 (tiga) siklus, pada setiap siklusnya terdiri dari tahap-tahap: perencanaan, tindakan, pengamatan/ pengumpulan data dan refleksi. Untuk memperoleh data aktivitas siswa menggunakan lembaran observasi, dan data hasil belajar diperoleh melalui tes tertulis. Dari hasil tindakan menunjukkan bahwa kerja kelompok dapat meningkatkan aktivitas dan hasil belajar siswa dalam pembelajaran Qur'an Hadits. Hasil tindakan pada aktivitas siswa rata-rata sebesar 92.50 (Siklus I), 92.92 (Siklus II), dan 93.55 (Siklus III), dan hasil belajar siswa 66,77 (Siklus I), 68,40 (Siklus II), dan 70,70 (Siklus III).

\section{Kata Kunci: Aktivitas, Hasil Belajar, Qur’an Hadits}




\section{PENDAHULUAN}

Siswa Madrasah Aliyah masih mengalami kesulitan menerima informasi yang bersifat abstrak dan simbol-simbol, anak akan lebih tertarik dan mengesankan pada hal-hal yang bersifak konkrit dan realistis. Pada mata pelajaran matematika, fisika banyak alat peraga, dan media pembelajaran yang dijual dipasaran, berbeda dengan mata pelajaran Qur'an Hadits, media dan alat pembelajaran tentu lebih banyak contoh kehidupan manusia sehari-harinya. Salah satu contoh yang sangat efektif dan mudah diterima oleh siswa yaitu dengan melalui kerja kelompok. Kerja kelompok merupakan suatu metode pembelajaran yang sering di gunakan dimana sekolah memiliki sarana dan prasarananya masih sangat minim, dan juga kerja kelompok tepat digunakan khususnya apabila tingkat kemampuan atau kecakapan siswa sangat heterogen.

Berdasarkan uraian di atas, perlu dilakukan suatu penelitian tindakan kelas apakah kerja kelompok dapat meningkatkan Aktifitas dan hasil belajar siswa.Bagaimanakah peningkatan Aktifitas belajar siswa melalui kerja kelompok? Bagaimana pula peningkatan hasil belajar siswa melalui kerja kelompok?

Dalam proses pembelajaran siswa dan guru dituntut adanya aktivitas, sebab tanpa adanya aktifitas keduanya baik guru maupun siswa tidak ada proses pembelajaran. Menurut Sardiman (2004:95) menyatakan proses belajar tidak akan terjadi apabila siswa hanya melakukan aktivitas fisik saja atau mental saja. Aktivitas yang melibatkan fisik atau mental dapat digolongkan: (1) Visual Activities. Yang didalamnya membaca, memperhatikan gambar, demonstrasi, percobaan dan pekerjaan oranglain, (2) Oral Activities, seperti menyatakan merumuskan, bertanya, memberikan saran, mengeluarkan pendapat, menga-dakan wawancara, diskusi, interupsi, (3) Listening Activities, seperti mende-ngarkan uraian, percakapan, diskusi, music dan pidato, (4) Writing Activities seperti menulis cerita, karangan, laporan, angket dan menyalin, (5) Drawing Activities, seperti meng-gambar, membuat grafik, peta dan diagram, (6) Motor Activities seperti melakukan percobaan, membuat konstrsuksi model, mereparasi, bermain, berkebun dan beternak, (7) Mental Activities seperti menanggapi, mengingat, memecahkan soal, meng-analisa, melihat hubungan dan mengambil keputusan, (8) Emotional Activities seperti menaruh minat, merasa bosan, gembira, bersema-ngat, bergairah, berani, tenang dan gugup.

Siswa dapat dikatakan aktif apabila tidak melakukan penyimpangan dalam (1) berbicara diluar pelajaran, (2) memandang kekiri dan kekanan, (3) mencari perhatian, (4) mengerjakan tugas lain, dan (5) keluar masuk kelas. Doran, RL (1995:80).

Sebagaimana yang diungkapkan Sardiman (2001:100) bahwa:Hasil belajar mencerminkan adanya perubahan tingkah laku pada siswa . Ketercapaian tujuan pembelajaran atau hasil pengajaran sangat dipengaruhi oleh bagaimana aktivitas siswa dalam belajar. Hasil belajar adalah bukti dari hasil usaha seseorang dalam melakukan kegiatan belajarnya. Menurut Arikunto, (1988:57) yaitu : Nilai yang di peroleh waktu ulangan bukan menggambarkan partisipasi tetapi menggambarkan hasil belajar. Karena dalam proses pembelajaran siswa harus adanya aktivitas, makin tinggi aktivitasnya maka makin tinggi pula hasil belajarnya. Sedangkan menurut Adjat Rokadjat dan Harnadi (lgso :5) memberikan pengertian belajar sebagai berikut : "Belajar adalah suatu proses usaha aktif yang dilakukan seseorang untuk memperoleh sesuatu hal yang mengakibatkan terbentuknya perubahan dalam pola-pola tingkah laku yang menyeluruh menuju kearah yang lebih meningkat dan lebih baik pada pribadi orang belajar, sebagai perubahan karena faktor reflektif, kematangan atau keadaan sementara". Melihat kondisi seperti ini guru dituntut untuk lebih berperan aktif dan selalu inovatif dalam proses pembelajaran agar siswa merasa senang dalam belajar dan lebih dinamis dalam kegiatan belajar dikelas.

Guru yang kreatif dan inovatif selalu berusaha memperbaiki kekurangan-kekurangan yang ada pada dirinya, dan selalu berusaha agar dalam proses pembelajaran selalu lebih menyenangkan dan lebih cepat diterima oleh siswa materi pembelajaran yang diberikan.

Kerja kelompok adalah metode pembelajaran dengan membagi tugas pembelajaran yang dikerjakan oleh kelompok. Menurut Winarno Surakhmad, Kerja Kelompok dapat dipakai untuk mencapai bermacam-macam tujuan :

(a) Pengelompokkan didasarkan atas perbedaan individual dalam kemampuan belajar. Hal ini diperlukan terutama apa-bila komposisi keanggotaan kelompok sangat heterogen ditinjau dari sudut kecakapan.(b) Pengelompokan atas dasar perbedaan individual dalam minat belajar. Pengelompokan ini dilakukan apabila untuk 
perkembangan setiap anak didik dianggap perlu untuk lebih banyak memberikan kesempatan mengembangkan minat masing-masing.(c) Penge-lompokan atas dasar fasilitas yang tersedia. Hal ini berlaku bila fasilitas pelajaran tidak sebanding dengan jumlah yang membutuhklan, sehingga secara praktis kelompok dibagi menurut adanya fasilitas, (d) Penge-lompokan atas dasar peningkatan partisipasi. Cara mengajar semacam ini dimaksudkan untuk merangsang setiap anak didik agar ikut serta dalam memecahkan masalah secara penuh dalam hubungan kelompok dan secara gotong-royong, (e) Pengelompokan atas dasar pembagian pekerjaan. Bila terdapat beberapa pokok yang perlu dipecahkan dalam waktu yang sama, maka kelompok dapat dibagi menurut jenis kebutuhan, dan masing-masing bertanggung jawab terhadap tugas khusus itu.

Metode kerja kelompok dapat membantu siswa yang secara kebetulan siswa tersebut kurang cukup sarana pembelajarannya, kurang mampu memcahkan masalah-masalah yang rumit, dan juga kerja kelompok dapat meningkatkan minat belajar siswa, karena siswa secara bergotong royong mengerjakan atau menyelesaikan tugas-tugas sekolah secara bersama-sama.

Pembelajaran kontekstual siswa dituntut berperan aktif dengan mengkaitkan pengetahuan yang dimiliki dengan lingkungan kehidupan di sekilingnya. Pende-katan Kontekstual melalui pembelajaran kelompok dapat meningkatkan aktifitas belajar dan hasil belajar siswa.

\section{B. TUJUAN PENELITIAN}

Adapun tujuan yang ingin dicapai melalui penelitian ini adalah: (1) Mendiskripsikan peningkatan aktivitas siswa dalam pembelajaran melalui kerja kelompok;(2) Mendiskripsikan peningkatan hasil belajar siswa dalam pembelaja-ran melalui kerja kelompok.

\section{METODE PENELITIAN}

Lokasi penelitian ini dilaksanakan pada siswa kelas XI MA Darul Ulum Sukoharjo Kabupaten Pringsewu. Penelitian dilaksanakan dikelas ini karena aktivitas siswa pasif dan hasil belajar Pendidikan Qur'an Hadits rendah. Penelitian ini dilaksanakan dalam 3 siklus, dalam setiap siklusnya menggunakan model Kemis dan Taggart, (1992) (dalam Depdiknas, 2004) yang terdiri dari beberapa tahapan yaitu : Merencanakan, melaksanakan tindakan, mengamati, merefleksi.
Penelitian ini adalah Penelitian Pembelajaran dikelas XII. MA Darul Ulum, dalam proses kajian dan tindakan akan ditempuh dalam 4 tahapan yaitu : Merencanakan, melaksanakan tindakan, mengamati, merefleksi.

Instrumen yang digunakan dalam penelitian ini ialah : Lembar soal tes, dan Lembar observasi. Untuk memperoleh data dalam penelitian ini dilakukan dengan cara menyiapkan lembar observasi yang telah disediakan dan selama proses pembelajaran berlangsung observer cukup memberi tanda checklist $(\sqrt{ })$ Lembar Observasi, Sedangkan data hasil belajar diperoleh melalu tes tertulis.

Indikator keberhasilan dalam penelitian ialah adanya peningkatan aktivitas dan hasil belajar siswa dalam setiap siklusnya.

\section{HASIL DAN PEMBAHASAN}

Hasil data penelitian dapat dilihat pada tabel 1 dan tabel 2 pada halaman berikutnya Pembelajaran pada Siklus I Pelaksanaan siklus (1) menghasilkan data aktivitas siswa dalam proses pembe-lajaran dengan menggunakan pendekatan kerja kelompok adalah sebagai berikut: Data di atas menunjukkan bahwa aktivitas siswa dalam kegiatan pembelajaran mencapai $45 \%$, yaitu $92,50 \%$ siswa melakukan kegiatan yang relevan dengan pembelajaran (On Task). Sedangkan siswa melakukan kegiatan yang tidak relevan dengan pembelajaran (Off Task) sebesar 7.50\%.

Sedangkan hasil mendapat nilai $\geq 66.57$ sejumlah 13 orang dan yang mendapat nilai $\leq$ 67 sebanyak 22 orang tidak ikut tes 2 orang. Kekurangan-kekurangan kinerja guru pada siklus I (satu) adalah disebabkan kurang mengarahkan siswa dalam kerja kelompok, kurang membimbing siswa dalam kerja kelompok, dan kurang memberikan penguatan hasil kerja kelompok, serta memberikan tindak lanjut belum cukup jelas. Dari evlauasi di atas maka kegiatan aktivitas guru pada siklus selanjutnya guru hendaknya lebih memperhatikan kekurangan-kekurangan yang ada.

Tabel : 1 Hasil Pengamatan Aktifitas Siswa

\begin{tabular}{|c|c|c|c|c|c|c|}
\hline \multirow{2}{*}{ No } & \multicolumn{2}{|c|}{$\begin{array}{c}\text { Persentase } \\
\text { Siklus I }\end{array}$} & \multicolumn{2}{c|}{$\begin{array}{c}\text { Persentase } \\
\text { Siklus II }\end{array}$} & \multicolumn{2}{c|}{$\begin{array}{c}\text { Persentase } \\
\text { Siklus III }\end{array}$} \\
\cline { 2 - 7 } & $\begin{array}{c}\text { Off } \\
\text { task }\end{array}$ & $\begin{array}{c}\text { On } \\
\text { task }\end{array}$ & $\begin{array}{c}\text { Off } \\
\text { task }\end{array}$ & $\begin{array}{c}\text { On } \\
\text { task }\end{array}$ & $\begin{array}{c}\text { Off } \\
\text { task }\end{array}$ & $\begin{array}{c}\text { On } \\
\text { task }\end{array}$ \\
\hline 1 & 0 & 100 & 0 & 100 & 0 & 100 \\
\hline 2 & $*$ & $*$ & 0 & 100 & 10 & 90 \\
\hline 3 & 20 & 80 & 20 & 80 & 20 & 80 \\
\hline
\end{tabular}




\begin{tabular}{|c|c|c|c|c|c|c|}
\hline 4 & 0 & 100 & 0 & 100 & 0 & 100 \\
\hline 5 & 10 & 90 & 10 & 90 & 10 & \begin{tabular}{|l|}
90 \\
\end{tabular} \\
\hline 6 & $*$ & $*$ & 10 & 90 & 10 & \begin{tabular}{|l|}
90 \\
\end{tabular} \\
\hline 7 & 0 & 100 & 0 & 100 & 0 & 100 \\
\hline 8 & 20 & 80 & 20 & 80 & 10 & 90 \\
\hline 9 & 30 & 70 & 30 & 70 & 30 & \begin{tabular}{|l|}
70 \\
\end{tabular} \\
\hline 10 & 0 & 100 & 0 & 100 & 0 & \begin{tabular}{|l|}
100 \\
\end{tabular} \\
\hline 11 & 0 & 100 & 0 & 100 & 0 & 100 \\
\hline 12 & 0 & 100 & 0 & 100 & 0 & \begin{tabular}{|l|l}
100 \\
\end{tabular} \\
\hline 13 & 0 & 100 & 0 & 100 & 0 & 100 \\
\hline 14 & 0 & 100 & 0 & 100 & 0 & \begin{tabular}{|l}
100 \\
\end{tabular} \\
\hline 15 & 0 & 100 & 0 & 100 & 0 & \begin{tabular}{|l|l|}
100 \\
\end{tabular} \\
\hline 16 & 0 & 100 & 0 & 100 & 0 & 100 \\
\hline 17 & * & * & 0 & 100 & 0 & 100 \\
\hline 18 & 0 & 100 & 0 & 100 & 0 & 100 \\
\hline 19 & 20 & 80 & 30 & 70 & 10 & 90 \\
\hline 20 & 30 & 70 & $*$ & $*$ & 20 & 80 \\
\hline 21 & 0 & 100 & 0 & 100 & 0 & \begin{tabular}{|l|l|}
100 \\
\end{tabular} \\
\hline 22 & 0 & 100 & 0 & 100 & 0 & 100 \\
\hline 23 & 30 & 70 & 30 & 70 & 30 & 70 \\
\hline 24 & 0 & 100 & 0 & 100 & 0 & \begin{tabular}{|l|l|}
100 \\
\end{tabular} \\
\hline 25 & 0 & 100 & 0 & 100 & 0 & \begin{tabular}{|l|l}
100 \\
\end{tabular} \\
\hline 26 & 0 & 100 & 0 & 100 & 0 & 100 \\
\hline 27 & 10 & 90 & $*$ & $*$ & 10 & \begin{tabular}{|l|}
90 \\
\end{tabular} \\
\hline 28 & 0 & 100 & 0 & 100 & 0 & 100 \\
\hline 29 & 20 & 80 & 10 & 90 & 20 & 80 \\
\hline 30 & 0 & 100 & 0 & 100 & 0 & 100 \\
\hline 31 & 0 & 100 & 0 & 100 & 0 & 100 \\
\hline 32 & 0 & 100 & 0 & 100 & 0 & 100 \\
\hline 33 & 0 & 100 & 0 & 100 & 0 & 100 \\
\hline 34 & 20 & 80 & 20 & 80 & 20 & 80 \\
\hline 35 & 0 & 100 & 0 & 100 & 0 & 100 \\
\hline 36 & 0 & 100 & 0 & 100 & 0 & 100 \\
\hline 37 & 0 & 100 & 0 & 100 & 0 & 100 \\
\hline 38 & 0 & 100 & 20 & 80 & 0 & 100 \\
\hline $\begin{array}{l}\text { Rata- } \\
\text { rata }\end{array}$ & 6.00 & 94.00 & 5.56 & 94.44 & 5.26 & $4^{94.7}$ \\
\hline
\end{tabular}

Keterangan : Prilaku siswa yang relevan dengan kegiatan pembelajaran (On-Task)

Waktu aktif (On-Task) adalah $100 \%$ dikurangi dengan waktu

Tabel: 2 Data Ketuntasan Siswa

\begin{tabular}{|c|c|c|c|c|c|c|}
\hline \multirow{2}{*}{$\begin{array}{l}\mathbf{N} \\
\mathbf{0}\end{array}$} & \multicolumn{3}{|c|}{$\begin{array}{c}\text { NILAI } \\
\text { SIKLUS }\end{array}$} & \multirow{2}{*}{\begin{tabular}{|c} 
NIL \\
AI \\
Rata- \\
Rata \\
\end{tabular}} & \multicolumn{2}{|c|}{ Kriteria } \\
\hline & I & $\begin{array}{l}\text { I } \\
\text { I }\end{array}$ & III & & $\begin{array}{c}\text { Tunt } \\
\text { as }\end{array}$ & Blm Tnts \\
\hline 1 & $\begin{array}{l}66 . \\
50\end{array}$ & $\begin{array}{l}6 \\
8 \\
\dot{0} \\
0\end{array}$ & 75.00 & $\begin{array}{c}69.8 \\
3\end{array}$ & $\begin{array}{c}\text { Tunt } \\
\text { as }\end{array}$ & \\
\hline 2 & $*$ & $\begin{array}{l}6 \\
4\end{array}$ & 68.00 & 44.17 & & $\begin{array}{l}\text { Belum } \\
\text { Tuntas }\end{array}$ \\
\hline 3 & $\begin{array}{l}65 . \\
50\end{array}$ & $\begin{array}{l}6 \\
6\end{array}$ & 71.50 & $\begin{array}{c}67.8 \\
3\end{array}$ & & $\begin{array}{l}\text { Belum } \\
\text { Tuntas }\end{array}$ \\
\hline
\end{tabular}

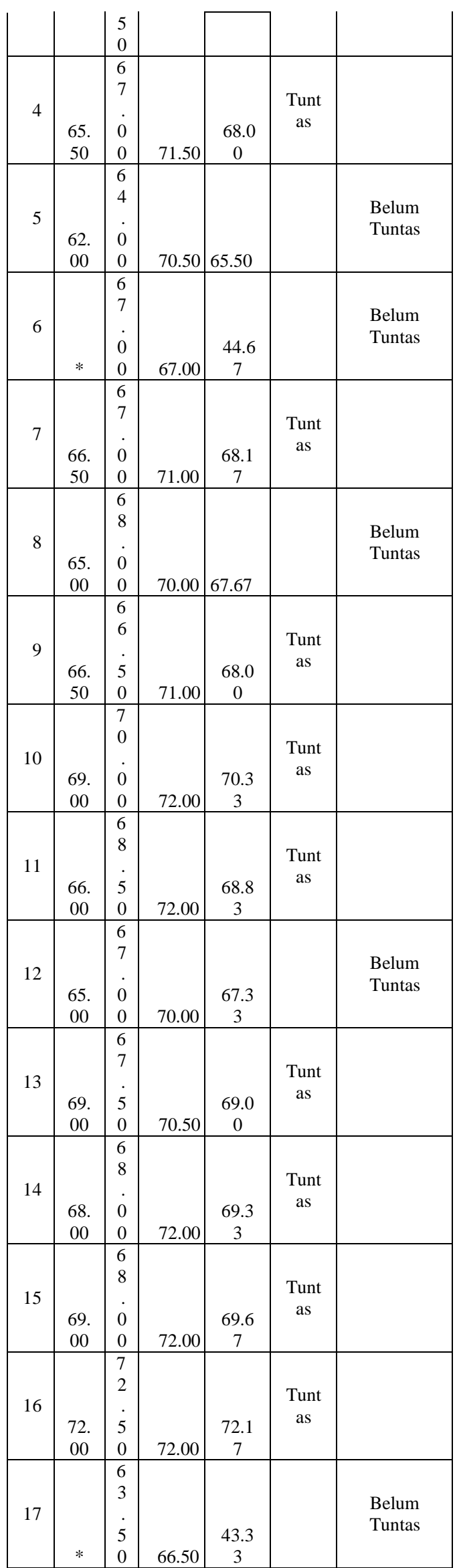




\begin{tabular}{|c|c|c|c|c|c|c|}
\hline 18 & $\begin{array}{c}70 . \\
00\end{array}$ & $\begin{array}{l}7 \\
1 \\
5 \\
5 \\
0 \\
\end{array}$ & 68.00 & 69.83 & $\begin{array}{c}\text { Tunt } \\
\text { as }\end{array}$ & \\
\hline 19 & $\begin{array}{l}67 . \\
50 \\
\end{array}$ & $\begin{array}{l}6 \\
8 \\
0 \\
0 \\
0\end{array}$ & 71.00 & 68.83 & $\begin{array}{c}\text { Tunt } \\
\text { as }\end{array}$ & \\
\hline 20 & $\begin{array}{l}67 . \\
00\end{array}$ & $*$ & 70.00 & $\begin{array}{c}45.6 \\
7 \\
\end{array}$ & & $\begin{array}{l}\text { Belum } \\
\text { Tuntas }\end{array}$ \\
\hline 21 & $\begin{array}{l}66 . \\
00\end{array}$ & $\begin{array}{l}6 \\
7 \\
. \\
0 \\
0\end{array}$ & 67.00 & $\begin{array}{c}66.6 \\
7\end{array}$ & & $\begin{array}{l}\text { Belum } \\
\text { Tuntas }\end{array}$ \\
\hline 22 & $\begin{array}{c}72 . \\
50\end{array}$ & $\begin{array}{l}6 \\
9 \\
. \\
5 \\
0\end{array}$ & 67.00 & 69.67 & $\begin{array}{c}\text { Tunt } \\
\text { as }\end{array}$ & \\
\hline 23 & $\begin{array}{c}73 . \\
00\end{array}$ & $\begin{array}{l}7 \\
3 \\
. \\
5 \\
0\end{array}$ & 79.50 & $\begin{array}{c}75.3 \\
3\end{array}$ & $\begin{array}{c}\text { Tunt } \\
\text { as }\end{array}$ & \\
\hline 24 & $\begin{array}{c}72 . \\
50\end{array}$ & $\begin{array}{l}7 \\
0 \\
. \\
5 \\
0\end{array}$ & 73.50 & $\begin{array}{c}72.1 \\
7\end{array}$ & $\begin{array}{c}\text { Tunt } \\
\text { as }\end{array}$ & \\
\hline 25 & $\begin{array}{c}70 . \\
50\end{array}$ & $\begin{array}{l}7 \\
0 \\
0 \\
0\end{array}$ & 72.50 & $\begin{array}{c}71.0 \\
0\end{array}$ & $\begin{array}{c}\text { Tunt } \\
\text { as }\end{array}$ & \\
\hline 26 & $\begin{array}{l}67 . \\
00\end{array}$ & $\begin{array}{l}6 \\
9 \\
0 \\
0\end{array}$ & 72.50 & $\begin{array}{c}69.5 \\
0\end{array}$ & $\begin{array}{c}\text { Tunt } \\
\text { as }\end{array}$ & \\
\hline 27 & $\begin{array}{c}61 . \\
50\end{array}$ & $*$ & 66.50 & $\begin{array}{c}42.6 \\
7\end{array}$ & & $\begin{array}{l}\text { Belum } \\
\text { Tuntas }\end{array}$ \\
\hline 28 & $\begin{array}{l}66 . \\
50\end{array}$ & $\begin{array}{l}6 \\
5 \\
5 \\
5 \\
0\end{array}$ & 67.50 & 66.50 & & $\begin{array}{l}\text { Belum } \\
\text { Tuntas }\end{array}$ \\
\hline 29 & $\begin{array}{l}67 . \\
00\end{array}$ & $\begin{array}{l}6 \\
5 \\
. \\
5 \\
0\end{array}$ & 65.50 & $\begin{array}{c}66.0 \\
0\end{array}$ & & $\begin{array}{l}\text { Belum } \\
\text { Tuntas }\end{array}$ \\
\hline 30 & $\begin{array}{l}67 . \\
00\end{array}$ & $\begin{array}{l}6 \\
9\end{array}$ & 71.00 & $\begin{array}{c}69.0 \\
0\end{array}$ & $\begin{array}{c}\text { Tunt } \\
\text { as }\end{array}$ & \\
\hline 31 & $\begin{array}{c}68 . \\
50\end{array}$ & $\begin{array}{l}6 \\
9 \\
. \\
0 \\
0\end{array}$ & 70.00 & $\begin{array}{c}69.1 \\
7\end{array}$ & $\begin{array}{c}\text { Tunt } \\
\text { as }\end{array}$ & \\
\hline 32 & $\begin{array}{l}70 . \\
00\end{array}$ & $\begin{array}{l}7 \\
1\end{array}$ & 72.00 & $\begin{array}{c}71.0 \\
0\end{array}$ & $\begin{array}{c}\text { Tunt } \\
\text { as }\end{array}$ & \\
\hline 33 & $\begin{array}{l}68 . \\
00\end{array}$ & $\begin{array}{l}6 \\
8\end{array}$ & 69.00 & $\begin{array}{c}68.3 \\
3 \\
\end{array}$ & $\begin{array}{c}\text { Tunt } \\
\text { as }\end{array}$ & \\
\hline
\end{tabular}

\begin{tabular}{|c|c|c|c|c|c|c|}
\hline & & $\begin{array}{l}0 \\
0 \\
\end{array}$ & & & & \\
\hline 34 & $\begin{array}{l}65 . \\
50 \\
\end{array}$ & $\begin{array}{l}6 \\
8\end{array}$ & 71.00 & 68.17 & $\begin{array}{c}\text { Tunt } \\
\text { as }\end{array}$ & \\
\hline 35 & $\begin{array}{l}69 . \\
50 \\
\end{array}$ & $\begin{array}{l}6 \\
9 \\
0 \\
0 \\
0\end{array}$ & 72.00 & $\begin{array}{c}70.1 \\
7 \\
\end{array}$ & $\begin{array}{c}\text { Tunt } \\
\text { as }\end{array}$ & \\
\hline 36 & $\begin{array}{c}72 . \\
00 \\
\end{array}$ & $\begin{array}{l}7 \\
3 \\
0 \\
0 \\
0\end{array}$ & 73.00 & $\begin{array}{c}72.6 \\
7 \\
\end{array}$ & $\begin{array}{c}\text { Tunt } \\
\text { as }\end{array}$ & \\
\hline 37 & $\begin{array}{l}71 . \\
00 \\
\end{array}$ & $\begin{array}{l}7 \\
2\end{array}$ & 72.50 & $\begin{array}{c}71.8 \\
3 \\
\end{array}$ & $\begin{array}{c}\text { Tunt } \\
\text { as }\end{array}$ & \\
\hline 38 & $\begin{array}{l}69 . \\
50 \\
\end{array}$ & $\begin{array}{l}7 \\
2 \\
0 \\
0 \\
0\end{array}$ & 72.50 & $\begin{array}{c}71.3 \\
3\end{array}$ & $\begin{array}{c}\text { Tunt } \\
\text { as }\end{array}$ & \\
\hline $\begin{array}{c}\mathrm{Ni} \\
\text { lai } \\
\text { rat } \\
\text { a- } \\
\text { rat } \\
\text { a } \\
\end{array}$ & $\begin{array}{l}67 . \\
93 \\
\end{array}$ & $\begin{array}{l}6 \\
8 \\
4 \\
9 \\
9\end{array}$ & 70.68 & $\begin{array}{c}69.0 \\
3 \\
\end{array}$ & $\begin{array}{c}\text { Tunt } \\
\text { as }\end{array}$ & \\
\hline & lah si & wa ' & intas & & & 12 \\
\hline & Pers & tas & & & & $31.58 \%$ \\
\hline
\end{tabular}

Pembelajaran pada Siklus II

Pelaksanaan siklus 2 ini menghasilkan data aktivitas siswa menunjukkan adanya peningkatan aktifitas dalam proses pembelajaran. Dari hasil observes ketercapaian aktivitas siswa dalam pembelajaran bahwa aktivitas siswa dalam kegiatan pembelajaran menunjukkan peningkatan meskipun baru mencapai $0,42 \%$, dibanding dengan siklus I. dan masih terdapat siswa yang tidak aktif dalam kegiatan pembelajaran. Hal ini dapat disebabkan dari dua faktor, yaitu factor dari luar siswa seperti guru itu sendiri kurang memberikan motivasi, juga faktor dari siswa itu sendiri yakni tidak memiliki minat untuk belajar. Hal ini disebabkan siswa masih suka berbicara di luar pelajaran, memandang kekiri dan kekanan, mencari perhatian, membaca buku mata pelajaran lain, mengerjakan tugas lain, mengganggu temannya, keluar masuk kelas. Sedangkan hasil pembelajaran diperoleh nilai rata-rata sudah mencapai 68.46 sudah mencapai 23 orang $(60,10 \%)$, dimana pada siklus I hanya 13 orang. Maka diharapkan pada siklus berikutnya guru lebih konsentrasi dalam usaha meningkatkan aktifitas siswa sehingga 
juga diharapkan hasil pembelajaran juga lebih meningkat.

\section{Pembelajaran pada Siklus III}

Pelaksanaan siklus III ini menghasilkan data aktivitas siswa menunjukkan adanya peningkatan aktifitas siswa dalam proses pembelajaran. Aktivitas siswa dalam kegiatan pembelajaran sudah menunjukkan peningkatan yang lebih baik di banding dengan siklus I ke II, pada siklus ini peningkatannya mencapai $0,63 \%$. Sejalan dengan hal tersebut hasil belajar siswa juga menunjukkan peningkatan baik aspek Penguasaan Konsep dan NilaiNilai, maupun aspek Penerapan, tabel data di atas menunjukkan bahwa hasil belajar pada siklus III nilai dari Penguasaan Konsep dan Nilai-Nilai, diperoleh nilai rata-rata 68.50 dan aspek Penerapan memperoleh nilai rata-rata 72.86 , dan nilai total rata-rata 70.68 ini berarti mengalami peningkatan rata-ratanya sebesar 3.34.Dari data hasil kaji tindak tiga siklus di atas menunjukkan selalu ada peningkatan hasil pembelajaran Qur'an Hadits dengan menggunakan pendekatan kerja kelompok.

Dari siklus ke siklus penelitian tindakan kelas yang telah dilaksanakan, dan telah dianalisis maka dapat diambil kesimpulan bahwa pembelajaran dengan kerja kelompok dapat meningkatkan aktifitas belajar siswa, hal ini dapat ditunjukkan dengan prosentase aktifitas siswa, pada siklus pertama memperoleh rata-rata $92.50 \%$, pada siklus kedua memperoleh rata-rata $92.92 \%$ dan pada siklus ketiga memperoleh rata-rata $93.55 \%$. Begitu halnya dengan hasil belajar siswa, kerja kelompok dapat meingkatkan hasil belajar siswa hal ini dapat dilihat dari hasil kegiatan pada siklus pertama memperoleh rata-rata $67.93 \%$ pada siklus kedua memperoleh ratarata $68,49 \%$ pada siklus ketiga memperoleh rata-rata $70.68 \%$. Kalau pada siklus I siswa belum mencapai ketuntasan dalam pembelajaran karena hanya 13 siswa dari 38 siswa dalam satu kelasnya atau hanya $45 \%$ saja yang mencapai ketuntasan. Dan pada siklus ke II mengalami peningkatan yakni sudah mencapai 23 orang atau $61 \%$, dan juga pada siklus III lebih meningkat lagi hingga 31 orang, atau $82 \%$ yang telah mencapai ketuntasan belajar.

\section{E. PENUTUP}

\section{1) Kesimpulan}

Berdasarkan hasil penelitian tindakan kelas yang telah dilaksanakan, dan telah dianalisis maka dapat diambil kesimpulan bahwa :

Pembelajaran dengan Kerja Kelompok dapat meningkatkan aktifitas belajar siswa, hal ini dapat ditunjukkan dengan prosentase aktifitas siswa, pada siklus pertama memperoleh rata-rata $92.50 \%$, pada siklus kedua memperoleh rata-rata $92.92 \%$ pada siklus ketiga memperoleh rata-rata $93.55 \%$.

Pembelajaran dengan kerja kelompok dapat meingkatkan hasil belajar siswa hal ini dapat dilihat dari hasil kegiatan pada siklus pertama memperoleh rata-rata $67.93 \%$ pada siklus kedua memperoleh rata-rata 68,49 \% pada siklus ketiga memperoleh rata-rata 70.68 $\%$

\section{2) Saran}

Berdasarkan kesimpulan di atas maka disarankan :

Pada proses pembelajaran Pendidikan Quran Hadits agar siswa tidak pasif, tidak bosan dan lebih bergairah maka disarankan agar menggunakan metode kerja kelompok.

Agar Kerja kelompok dapat berhasil dengan baik maka disarankan agar dalam pembagian dan pembentukan kelompok supaya siswa diatur dan dibimbing sedemikian rupa sehingga penyebaran siswa malas, serta yang rajin dan pandai lebih merata, tidak terjadi adanya group pandai, atau group malas, dan group rajin.

\section{DAFTAR PUSTAKA}

Adjat Rokadjat dan Hermadi D 1980. Pengantar kearah Pemahaman Belajar Publikasi Jurusan PPB FIP IKIP Bandung

Arikunto, S. 1988. Dasar-Dasar Evaluasi Pendidikan. Bina Aksara: Jakarta

Doran, RL., 1995. Basic Meansurement and evaluation of instruction Science. National Science Teaching Association. New York

Sardiman .A.M. 2004 Interkasi dan Motivasi Belajar Mengajar. Grafindo Persada. Jakarta

Undang-undang Republik Indonesia Nomor 14 Tahun 2005 tentang Guru dan Dosen(2006) Tamita Utama. Jakarta

Winarno Surakhmad 1982 Pengantar Interaksi Mengajar-Belajar Dasar dan Teknik Metodologi Pengajaran, Tarsito Bandug 
